\title{
Modelling Spatial Pattern of Anemia and Malnutrition Co-occurrence Among Under-five Children in Ethiopia: A Bayesian Geostatistical Approach
}

\section{Osafu Augustine Egbon}

Universidade de São Paulo

\author{
Asrat Mekonnen Balechew ( $\nabla$ asrat@usp.br) \\ Ambo University \\ Mariella Ananias Bogoni \\ Universidade Federal de São Carlos
}

\section{Research Article}

Keywords: SPDE, anemia, malnutrition, geostatistical analysis, Ethiopia

Posted Date: November 2nd, 2021

DOI: https://doi.org/10.21203/rs.3.rs-1015108/v1

License: (c) (1) This work is licensed under a Creative Commons Attribution 4.0 International License.

Read Full License 


\title{
RESEARCH
}

\section{Modelling Spatial Pattern of Anemia and Malnutrition Co-occurrence among Under-five Children in Ethiopia: A Bayesian Geostatistical Approach}

\author{
Osafu Augustine Egbon ${ }^{1,3}$, Asrat Mekonnen Balechew ${ }^{1,2 *}$ and Mariella Ananias Bogoni ${ }^{1,3}$ \\ ${ }^{1}$ Institute of Mathematical and Computer Sciences, University of São Paulo, São Carlos, Brazil \\ ${ }^{2}$ Department of Mathematics, Ambo University, Ambo, Ethiopia \\ ${ }^{3}$ Department of Statistics, Universidade Federal de São Carlos, São Carlos, Brazil
}

\footnotetext{
${ }^{*}$ Correspondence: asrat@usp.br ${ }^{2}$ Department of Mathematics, Ambo University, Ambo, Ethiopia Full list of author information is available at the end of the article
}

\begin{abstract}
Background: Anemia and Malnutrition among under-five children are one of the major challenges to public health in Ethiopia. While anemia is responsible for delayed child development and growth, malnutrition is associated with the high infant mortality rate in Ethiopia.

Method: This study aims to determine the socio-economic, demographic, and geographical risk factors that simultaneously increase the co-occurrence of anemia and malnutrition among under-five children in Ethiopia. Geostatistical data was obtained from the Ethiopia Demographic and Health Survey for 2011 and 2016. A Bayesian hierarchical linear mixed model was adopted using the stochastic partial differential equation to estimate the spatial pattern of the co-occurrence of anemia and malnutrition in Ethiopia.
\end{abstract}

Result: The findings revealed that gender, maternal education, number of children under five, birth order, preceding birth, contraceptive use, vaccination, marital status, birth weight, diarrhea, and fever are significant risk factors of the co-occurrence of anemia and malnutrition. The findings also reveal the vulnerability of under-five children to the co-occurrence of anemia and malnutrition within the first twenty months after birth and young maternal age. Regarding the geographical aspect, this study found a geographical disparity in the prevalence of anemia and malnutrition in Ethiopia. The highest burden of the co-occurrence of anemia and malnutrition lies in the Northern Gambela, Western Oromia, Northeast Benishangul-gumuz, Central and Northern Amhara, Southern Afar, and parts of Somali.

Conclusion: These findings could be utilized by policymakers and intervention programs to simultaneously tackle and contain the prevalence of both anemia and malnutrition. For cost-effective intervention, policies and programs that improve individual-level risk factors of parents and caregivers are a more promising approach to tackle high prevalent regions than the ones on the children and should be considered as an utmost priority in the country.

Keywords: SPDE; anemia; malnutrition; geostatistical analysis; Ethiopia 


\section{Background}

Malnutrition is a global health challenge correlated with prevalence and death among children, particularly in developing countries. A consequence of malnourishment in children is the high susceptibility to illness, as malnutrition reduces the immunity to resist infectious agents [1]. It gives room for infectious diseases such as vector-borne disease, diarrhea, anemia, and respiratory infections [2, 3]. Malnutrition could lead to death, impaired growth, immunodeficiency, which causes the body system to lack biological defense mechanisms. It brings a social and economic burden to public health. As a result, children have adverse consequences throughout the life course, such as short adult height, lower attained schooling, low school attendance, and poor work performance $[4,5]$.

According to [1], 149 million under-five children were stunted, 50 million were considered wasted, and 40 million children were categorized as underweight in the world. In Eastern and Southern Africa, 29 million under-five children were stunted, 5.4 million were wasted, and 3.6 million were underweight. Though the decline in stunting and wasting prevalence in East Africa between the years 2000 and 2018 respectively dropped from $45.5 \%$ to $35.2 \%$ and $7.1 \%$ to $2.2 \%$, malnutrition remained a burden in Ethiopia [6]. According to [1], the prevalence of stunting in Ethiopia decreased from 51\% to $37 \%$ between 2005 and 2019, wasting diminished from $12 \%$ to $7 \%$ over the same period, and the percentage of underweight children has consistently decreased from $33 \%$ to $21 \%$. However, the current prevalence is considered severe according to WHO thresholds [6].

Studies have been conducted to determine the spatial patterns of malnutrition of children below age five in highly prevalent sub-Saharan African regions. For instance, [7] adopted Geo-additive Gaussian and latent variable models to account for childhood malnutrition in Egypt; [8] studied the spatial distributions of childhood under-nutrition in the Democratic Republic of Congo (DRC) by using geo-additive semi-parametric mixed model; [9] adopted a Bayesian quantile regression to determine the risk factors and spatial distribution of child's malnutrition at different quantiles in Nigeria; [10] employed multi-scale geographically weight regression (MGWR) to examine the spatial pattern of childhood malnutrition and investigated the spatial heterogeneity in the socio-economic features and childhood malnutrition in Uganda; [11] adopted a spatially weighted generalized linear mixed model to account for the Carbon (IV) Oxide $\left(\mathrm{CO}_{2}\right)$ concentration effect on childhood malnutrition in Nigeria and their study revealed that highly $\mathrm{CO}_{2}$ concentrated regions were at greater risk of malnutrition in Nigeria.

Investigations of malnutrition indicators among under-five children in Ethiopia have gained attention in recent years. For instance, [12] adopted a Bayesian semiparametric model to investigate the prevalence of malnutrition in Ethiopia; [13], and [14] examined the significance of geographical location to childhood undernutrition in Ethiopia. Specifically, the formal used a univariate quantile interval model to account for the risk factors of malnutrition, while the latter used a multivariate logistic mixed model to account for the joint spatial effect of stunting, wasting, and underweight.

Anemia is a condition of a low-level concentration of hemoglobin ( $\mathrm{Hb})$ in the blood [15]. As a result, the body tissues have a limited supply of oxygen and thus, function 
at low capacity. Nutritional deficiencies, particularly iron deficiency, folate (lack of enough folic acid), vitamins A and B12 are common causes of anemia $[15,16]$. Anemia is also responsible for delayed psychomotor development, impaired growth, immunodeficiency, and impaired cognitive performance among infants [17, 18].

As reported in [16], anemia is one of the major public health hazards detrimental to young children under age 5 years. Globally, WHO revealed that the prevalence of anemia in under-five children was $39.8 \%$ in 2019, and it is worsened in the Africa region as $60.2 \%$ were anemic [19]. In Eastern Africa, approximately $75 \%$ of underfive children suffer from anemia [20]. In Ethiopia, the prevalence of anemia in underfive children is more than $57 \%$ [21].

For decades, several studies have been conducted to determine the factors affecting the occurrence of anemia in under-five children in sub-Saharan African countries. For instance, [22] adopted a semi-parametric approach within the Bayesian framework to study the influence of socio-economic, demographic factors and geographical locations of on under-five hemoglobin level and anaemia in Nigeria; [23] examined spatial patterns and identify determinants of anaemia in Ethiopia using multilevel logistic regression model and it's spatial dependence using Moran's I statistic test; [24] studied the spatial spread and prevalence of under-five anaemia in selected African countries using a multi-variable hierarchical Bayesian geo-additive model; [25] identified the factors associated with anemia among under-five children in Guinea using spatial binomial logistic regression method via Bayesian estimation approach, and [26] studied the spatial distribution and factors associated with childhood anemia in Ethiopia using a mixed effect logistic regression model.

It is economical if prior to planning or implementation of intervention programs the risk factors that simultaneously increase the risk of anemia and malnutrition or the regions where both ailments are most prevalent are identified. In this manner, practitioners and policymakers could devise an intervention strategy without missing the opportunity to attend to both ailments simultaneously. However, inferences based on a single analysis are not sufficient to determine the factors simultaneously increasing the risk of anemia and malnutrition since the potency of the risk factors vary across different single analyses, and thus, cannot be compared side-by-side. It is more intuitive to account for these common risk factors in a joint analysis since it allows for better quantification of uncertainty in the co-occurrence of both ailments.

Several studies have been conducted to determine the key determinant factors of the co-occurrence of malnutrition and anemia among under-five children. For instance, [27] investigated the risk factors and the joint spatial distributions of anemia and malnutrition among children in sub-Saharan Africa using a generalized linear mixed model, [28] used multivariate logistic regression analysis to quantify the interrelation of malnutrition and anemia and determine the socio-demographic and socio-economic factors among school children in two elementary schools in Durbete Town, northwest Ethiopia, and [29] studied the prevalence of anemia and malnutrition among children aged 6-23 months in midland and lowland agro-ecological zones of rural Ethiopia.

Studies on the co-occurrence of anemia and malnutrition in Ethiopia have not gained considerable attention. Previous studies have only focused on sub-regions of Ethiopia [28, 29]. Moreover, in many studies, the binary outcomes of anemia and 
malnutrition are utilized in a multilevel logistic model to determine the risk factors of both ailments. However, loss of information is inevitable in the process of discretizing a continuous measurement of hemoglobin and malnutrition indicators, which has the potential to influence model uncertainty measurement and reduce model efficiency. Thus, this study aims to determine the socio-economic, demographic, and geographical risk factors predicting the co-occurrence of anemia, stunting, and wasting among under-five children in Ethiopia using continuous hemoglobin and malnutrition outcome variables. In this way, variations in the observed set are fully incorporated into the modeling framework. A Bayesian hierarchical linear mixed model was adopted, using the stochastic partial differential equation (SPDE) to determine the spatial pattern of the co-occurrence of anemia, stunting, and wasting in Ethiopia. The SPDE model allows continuous interpolation of prevalence over the whole country. Thus, it facilitates the spatial localization of hotspots regions in the country.

\section{Methods}

\section{Study Area and Data Collection}

In this study, the aim is to analyze the malnutrition and anemia indicators in Ethiopia. The Demography and Health Surveys (DHS) program gave access to the data set used for this study. The Ethiopia Demographic and Health Research Program (EDHS) is responsible for collecting and providing representative data on the population trends and health indicators.

The survey was planned to provide information on the main demographic and health indicators at the national and regional levels. This study combined the data from the 2011 and 2016 EDHS data to improve inference. The sampling frame was the list of enumeration areas (EAs) from the 2007 Ethiopia Population and Housing Census (PHC). A two-stage cluster design sampling scheme was adopted in both years. In the first stage, 624 (187-urban, 437-rural) and 645 (202-urban, 443-rural) EAs were selected in the 2011 and 2016 EDHS, considering the sampling probability proportionate to EA size. In the second stage, 29 households were selected in each EA through a systematic sampling with equal probability. In the survey, 17,817 $(18,008)$ households were selected in 2011 (2016). The total interviewed household was $16,515(16,650)$. The response rate was $95(98) \%$, of which all women aged 15-45 were eligible for interview [30, 21]. After data cleaning, 7449 (8159) children were included in the analysis.

\section{Statistical Method}

Let $Y_{1 i}$ be a random variable that represents the $\mathrm{Hb}$ indicator of children included in the survey, and let $Y_{2 i}$ be a random variable that represents the malnutrition indicator, such as height-for-age (HA) or weight-for-height (WH), of the same child. Suppose that, $Y_{1 i} \sim N\left(\mu_{1 i}, \tau_{1}^{-1}\right)$ and $Y_{2 i} \sim N_{2}\left(\mu_{2 i}, \tau_{2}^{-1}\right)$. By construction, HA and WA are standardized indicators and thus are unitless. Hence, we standardized Hb using the WHO hemoglobin threshold for anemia to have better uncertainty estimates. This study is aimed to determine the key risk factors that significantly increase the prevalence of low functional $\mathrm{Hb}$ and malnutrition indicators simultaneously. Thus, 
we extended the location parameter $\boldsymbol{\mu}$ as a linear predictor of socio-economic, demographic, and geographical variables. Let $\mathbf{y}=\left\{\mathbf{y}_{1}, \mathbf{y}_{2}\right\}$ be a stacked realization of the indicators, and considered the following structural additive linear predictors:

$$
\begin{aligned}
& \mu_{1 i}=\mathbf{x}_{i}^{T} \boldsymbol{\beta}_{1}+\sum_{j=1}^{J} f_{1 k}\left(u_{i k}\right)+f\left(v_{i}\right), \\
& \mu_{2 i}=\mathbf{x}_{i}^{T} \boldsymbol{\beta}_{2}+\sum_{j=1}^{J} f_{2 k}\left(u_{i k}\right)+f\left(v_{i}\right), i=1,2 \ldots, n,
\end{aligned}
$$

$\mathbf{x}_{k i}$ is a $p \times 1$ design vector of linear covariates, such as maternal education level, gender, household wealth index, etc. $\boldsymbol{\beta}$ is a $p \times 1$ vector of fixed effects, $\left\{f_{k}\right\}$ represents an unknown nonlinear function for the random effect covariates $\mathbf{u}$, such as maternal and child age. $f$ is a function that accounts for the spatial effect, and $\mathbf{v}$ is the geographical coordinate where data were observed.

Among the covariates included in the analysis, mothers' age and child's age were allowed to have a nonlinear relationship to the two indicators. Consequently, we model the two factors with a random walk of order two prior, and it is defined as follows. Let $\mathbf{u}_{k}$ be the covariate variable identifying child's $(k=1)$ and mother's $(k=2)$ age. Given $\mathbf{z}=\left(u_{k 1}, u_{k 2}, \ldots, u_{T}\right)$ a Gaussian vector is constructed assuming independent second-order increment. Define

$$
\Delta_{u_{k t}}^{2}=u_{k t}-2 u_{k(t+1)}+u_{k(t+2)} \sim N\left(\mathbf{0}, \sigma_{u_{k}}^{2}\right),
$$

therefore, the joint distribution of $\mathbf{u}_{k}$ is given as

$$
\pi(\mathbf{z}) \propto\left(\frac{1}{\sigma_{u_{k}}^{2}}\right)^{(n-2) / 2} \exp \left\{-\frac{1}{2 \sigma_{u_{k}}^{2}} \mathbf{u}_{k}^{T} \mathbf{R} \mathbf{u}_{k}\right\}
$$

where $\mathbf{R}$ is the structure matrix reflecting the stochastic neighborhood structure of the Gaussian random walk 2. The child and mother's age were ordered at regular intervals from month 0 to 59 , and year 15 to 49 respectively. Specifically, $t \in\{0,1, . ., 59\}$ for child's age, and $t \in\{15,19, \ldots, 49\}$ for mother's age. Thus, $y_{k t}$ represents the effect at time $t$. The order two random walk is pliable given its invariance in the addition of a linear term to $u_{k t}$, and gains computational benefits due to the exhibition of Markov property [17].

To account for the spatial effect, this study took a closer view of each region across the country. For confidentiality purposes, the enumeration areas were used as the point referenced data in place of household reference. The mesh representation of Ethiopia is shown in Figure 1. The points (blue and red) represent the enumeration areas included in the 2011 and 2016 surveys. Moreover, the red dots represent the EAs where household surveys were conducted for both years, while the blue dots represent the EA where only 2011 surveys were conducted. The Stochastic Partial Differential Equation (SPDE) [31] was adopted to model the spatial effect of the prevalence of the indicators. In other words, $f_{\text {spat }}$ was assigned an SPDE prior model. The SPDE is given as

$$
\left(\kappa^{2}-\Delta\right)^{\alpha / 2}(\tau f(\mathbf{v}))=\mathcal{E}(\mathbf{v})
$$




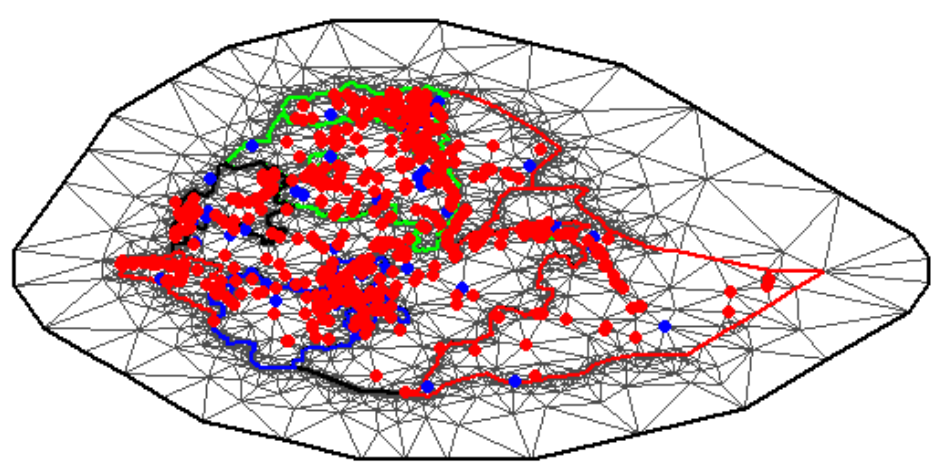

Figure 1: A mesh representation of Ethiopia map. The points indicate the location where data were collected. The red points is the location of the enumeration areas where data were collected in 2011 and 2016, while the blue points indicates the enumeration areas where only 2011 data were collected.

whose solution is a Gaussian Markov Random Field (GMRF) with a Matern covariance function defined as

$$
\operatorname{Cov}\left(f\left(v_{i}\right), f\left(v_{j}\right)\right)=\frac{\sigma^{2}}{2^{\nu} \Gamma(\nu)}\left(\kappa\left\|v_{i}-v_{j}\right\|\right)^{\nu} K_{\nu}\left(\kappa\left\|v_{i}-v_{j}\right\|\right), \sigma^{2}=\frac{\Gamma(\nu)}{\Gamma(\alpha)(4 \pi)^{d / 2} \kappa^{2 \nu} \tau^{2}},
$$

where $\Delta$ is the Laplacian, $\kappa$ is the parameter that controls the spatial scale and $\alpha$ controls the smoothness $\tau$ determines the variance, $K_{\nu}$ is a Basel function of the second kind, and $\|a-b\|$ is the euclidean distance between locations $a$ and $b$.

Lindgren and Rue [17] provided a sparse representation of the solution to SPDE on a two-dimensional mesh in Figure (1), which is represented as

$$
f(\mathbf{v})=\sum_{k=1}^{K} \psi_{k}(\mathbf{v}) \mathbf{w}_{k},
$$

where $\left\{\boldsymbol{\psi}_{k}\right\}$ is a set of bases function for the approximation of the solution and for projection into unobserved regions, and $\left\{\mathbf{w}_{k}\right\}$ is a latent variable with Gaussian distribution. The penalized complexity (PC) prior distribution was assigned to $\sigma$ and the range parameter $\rho=(8 \nu)^{1 / 2}$. For $\sigma$, the PC prior distribution with parameter $\sigma_{0}$ and $\alpha_{0}$ such that $P\left(\sigma>\sigma_{0}\right)=\alpha_{0}$ is given as

$$
\pi(\sigma) \propto \frac{\lambda}{2}\left(\sigma^{2}\right)^{3 / 2} \exp \left(-\lambda\left(\sigma^{2}\right)^{1 / 2}\right) .
$$


The $\mathrm{PC}$ prior for the range parameter $\rho$ is analogous to the one defined in Equation 6. A vague multivariate normal prior was assigned to $N(\boldsymbol{\beta} ; \mathbf{0}, \Sigma)$ and $N(\psi ; \mathbf{0}, \Sigma)$, where $\Sigma=100 \mathbf{I}$.

We formulated a Gaussian latent field model from the structured additive predictors 1 as $\mathcal{X}=\left\{\boldsymbol{\beta}_{1}, \mathbf{A},\left\{b_{k}\right\}\left\{f_{k}\right\}, f\right\}$ with a multivariate Gaussian prior distribution. In this way, the latent field $\mathcal{X}$ forms a Gaussian Markov random field with a sparse precision matrix $\mathbf{Q}\left(\boldsymbol{\theta}_{2}\right)$. Let $\pi(\boldsymbol{\theta})$, be a prior distribution assigned to $\boldsymbol{\theta}$, where $\boldsymbol{\theta}=\left(\boldsymbol{\theta}_{1}, \boldsymbol{\theta}_{2}\right), \boldsymbol{\theta}_{1}=\left(\tau_{1}, \tau_{2}\right)$, and $\boldsymbol{\theta}_{2}$ is a vector of hyperparameters for the prior models on the components of the latent field $\mathcal{X}$. Thus, the joint posterior of the latent field and the vector of hyperparameters is given as

$$
\pi(\mathcal{X}, \boldsymbol{\theta} \mid \mathbf{y}) \propto \pi(\boldsymbol{\theta}) \pi(\mathcal{X} \mid \boldsymbol{\theta}) \prod_{j=1}^{2} \prod_{i=1}^{n} \pi\left(y_{i j} \mid \mathcal{X}, \boldsymbol{\theta}\right)
$$

Since our interest is to make inferences from the marginal distribution of the latent field $\pi(\mathcal{X} \mid \mathbf{y})$ and the hyperparameters $\pi(\boldsymbol{\theta} \mid \mathbf{y})$, INLA, proposed by [31], stands as a computationally efficient and accurate method. Thus, this study used the R-INLA package in $\mathrm{R}$ [32] for the computation of the posterior marginals.

In the modeling framework using R-INLA, the multiple likelihood approach was adopted. Consider a $2 n \times 2$ matrix $Y$. The first $n$ rows of the first column contain the standardized $\mathrm{Hb}$ level of children, and the second column of these rows contains NA. Analogously, the second column of the remaining rows of $Y$ contains a malnutrition indicator (either Height-for-age or Weight-for-height), and the first column of these rows contains NA. In this manner, the effects in the structural additive model are readily obtained.

All methods were carried out in accordance with relevant guidelines and regulations.

\section{Results}

We first test the association of the co-occurrence of anemia, stunting, and wasting using a Chi-Square test of Independence. Additionally, the unconditional paired exact test (UPET), described in [cite ], was also adopted to check the differences between the proportion of children having both anemia and stunting, and anemia and wasting. Each of the continuous response variables was categorized based on the WHO threshold. That is, $y_{1} \leq 11$ and $y_{2} \leq-2$ were used to discretized the continuous observed values $y_{1}$ and $y_{2}$ into binary for $\mathrm{Hb}$ and malnutrition indicators. The formulated hypothesis at $5 \%$ level of significance is as follows:

$H_{0}$ : There is no association between anemia and malnutrition

$H_{1}$ : There is an association between anemia and malnutrition.

Due to the non-linearity exhibited by the two indicators at different age groups, we divided the data by age groups and test the formulated hypothesis. The test results are presented in Table 1.

Table 1 presents the observed frequencies of anemia and malnutrition indicators (stunting and wasting), the chi-square p-value, and the p-value of UPET. Jugging by the Chi-square test of independence with $5 \%$ level of significance, we have the 
Table 1: Chi-square test of association between the prevalence of anemia and malnutrition. The table also present a UPET test for the difference in the proportion of anemia and malnutrition. The age-group with a $\mathrm{p}$ value less than $5 \%$ is considered significant.

\begin{tabular}{|c|c|c|c|c|c|c|}
\hline & \multicolumn{2}{|c|}{$\begin{array}{c}\text { Anemia } \\
\text { Observed frequency }\end{array}$} & \multirow[t]{2}{*}{$\mathcal{X}^{2}$-P value } & UPET-P value \\
\hline \multirow{7}{*}{ Stunting } & Age & & No & Yes & & \multirow{3}{*}{0.000} \\
\hline & $6-20$ months & No & 1851 & 1019 & 0.8461 & \\
\hline & \multirow{3}{*}{$21-40$ months } & & & & \multirow{3}{*}{0.000} & \\
\hline & & No & 1701 & 1134 & & \multirow{2}{*}{0.000} \\
\hline & & Yes & 1547 & 1480 & & \\
\hline & \multirow{2}{*}{ 41-59 months } & No & 2133 & 755 & \multirow[t]{2}{*}{0.000} & \multirow{2}{*}{0.000} \\
\hline & & Yes & 1586 & 837 & & \\
\hline \multirow{6}{*}{ wasting } & \multirow{2}{*}{$6-20$ months } & No & 1573 & 2136 & \multirow[t]{2}{*}{0.000} & \multirow{2}{*}{0.000} \\
\hline & & Yes & 238 & 518 & & \\
\hline & \multirow[b]{2}{*}{$21-40$ months } & No & 3005 & 243 & \multirow[t]{2}{*}{0.000} & \multirow[b]{2}{*}{0.000} \\
\hline & & Yes & 2270 & 344 & & \\
\hline & \multirow{2}{*}{$41-59$ months } & No & 3448 & 1396 & \multirow[t]{2}{*}{0.000} & \multirow{2}{*}{0.000} \\
\hline & & Yes & 271 & 196 & & \\
\hline
\end{tabular}

statistical reason to conclude that there is an association between anemia and malnutrition indicators, except for age 6-20 months of stunting indicator. Also, the unconditional paired exact test to examine the difference in the proportion of anemia and malnutrition across the age groups indicated that the difference in the proportion of anemia and malnutrition among children is significantly different from zero. This indicates that the frequency of occurrence of anemia in children is statistically different from the occurrence of stunting, and wasting.

Prior to presenting the pairwise joint modeling of anemia and malnutrition, we first present the analysis results of anemia, stunting, and wasting within a single modeling framework.

Single analysis of Anemia and Malnutrition

Table 2 presents the results of the linear effect of anemia, stunting, and wasting. This study used the hemoglobin level, height-for-age, and weight-for-height outcome variables instead of the usual binary representations, in an attempt to capture the entire variations of the ailments among children. The table presents the posterior mean, standard deviation, and the $95 \%$ credible intervals. For each of the risk factors, "Reference" is used to indicate the reference category. The significance of the risk factors was determined by the non-inclusion of zero in the credible interval. Given the structural additive form, the lower the estimated coefficient of the risk factors, the higher the prevalence and risk of anemia, stunting, or wasting.

From Table 2, the prevalence of low $\mathrm{Hb}$ is significantly higher for male children compared with their female counterparts. It implies that male children are more at risk of anemia compared with female children. A similar result is obtained for stunting and wasting. The prevalence of low Hb level among children whose mothers 
have at least primary education is significantly lower compared with children whose mothers have no formal education. Additionally, as the mother's education level increases, the prevalence of low $\mathrm{Hb}$ level decreases, and thus, the risk of anemia decreases. A similar result is also obtained for stunting and wasting. It is expected since educated mothers are more enlightened about the child's development and are more likely to seek expert advice on the child's health and engage in a positive parental practice, [33]. Similarly, the prevalence of low $\mathrm{Hb}$ among under-five children whose household wealth quantile is at least poorer is significantly lower compared with children whose household wealth quantile is poorest. As the wealth quantile increases, the $\mathrm{Hb}$ level increases, and consequently the risk of anemia decreases. This result is similar to stunting and wasting. Thus, lower maternal education and lower wealth quantile increase the risk of anemia, stunting, and wasting.

Improved water source significantly lowers the prevalence of low $\mathrm{Hb}$ compared with their unimproved counterpart. Thus, an improved water source minimizes the risk of anemia. Improved toilet facility significantly reduces the prevalence of stunting compared with unimproved toilet systems. However, it is insignificant for the prevalence of anemia and wasting. Surprisingly, the prevalence of wasting among under-five children living in the Urban settlement is significantly higher compared with those living in the rural settlement. However, the prevalence of anemia and stunting among under-five children in the urban and rural regions is not significant. The result shows that stunting and wasting are significantly less prevalent among under-five children whose parents listen to at least one media means such as newspapers, television, or radio programs, compared with those whose parents do not listen to any media. However, for anemia, the prevalence of low $\mathrm{Hb}$ is not significant.

Stunting and wasting are significantly more prevalent among under-five children who had diarrhea or fever. Unlike diarrhea, in the presence of fever, the prevalence of low $\mathrm{Hb}$ increases, and consequently, the risk of anemia increases. That is, children having fever are more at risk of anemia, stunting, and wasting compared with those without fever. However, this is not the case for children with cough in the last two weeks before the survey, as there is no significant difference between the prevalence of anemia, stunting, and wasting among under-five children with or without cough.

The result indicates that the prevalence of low $\mathrm{Hb}$ is higher for children whose household has at least two children under five years old compared with children whose household has one child below five years of age. The higher the number of children under five years old, the higher the risk of low $\mathrm{Hb}$, and consequently, the higher the risk of anemia. This could be due to the effect of increased household burden and shared resources among the children. However, this is not significant for stunting and wasting, except that the prevalence of stunting significantly decreases for children whose household has more than four children below age five compared with children whose household has a single child. The prevalence of low Hb level among firstling children is significantly lower compared with second to fourth positions in the household. Moreover, the prevalence is significantly higher for the fifth position and above compared with children in the second and third positions in the household. It indicates that the risk of anemia increases with an increase in the order of birth. Stunting is significantly less prevalent among firstlings compared with 
the second to fourth positions. However, it is not significant for the fifth position and above. For wasting, the prevalence among firstlings is not significantly different from second to the fourth position, and however, it is more prevalent for the fifth position and above. Thus, higher birth position increases the risk of anemia, stunting, and wasting.

Stunting and low $\mathrm{Hb}$ level are significantly less prevalent among under-five children whose mother had preceding birth more than 25 months compared with underfive children whose mother had preceding birth below 25 months. In general, as the number of months of preceding birth increases, the prevalence of low $\mathrm{Hb}$ level and stunting decreases. Thus, children whose mothers had less than 25 months preceding birth are at higher risk of anemia and stunting. However, it is not significant for wasting. Surprisingly, the prevalence of low Hb levels among under-five children who utilize antenatal care service once is significantly lower compared with the prevalence among under-five children who visited the antenatal care service twice to three times. The reverse is the case for stunting, where higher visits significantly lower the risk of stunting. However, for wasting, the prevalence between all the categories is not significant. It could be associated with the differences in cultural beliefs, where parents have the notion only to visit the health service when there are health complications. Similarly, the Low Hb level and wasting prevalences among under-five children who utilize postnatal health care are not significantly different from under-five children who do not utilize the postnatal health care service. However, the prevalence of stunting is significantly lower among under-five children who utilize postnatal health care services.

The prevalence of low Hb level, stunting, and wasting among children whose parents use modern contraceptive is significantly lower compared with children whose parents do not use contraceptives. The prevalence of anemia and stunting among under-five children whose parents use traditional contraceptive methods is not significantly different from those children whose parents do not use contraceptives. However, the prevalence is significantly lower for wasting. This result indicates that the use of modern contraceptives significantly lowers the risk of these ailments. The prevalence of low $\mathrm{Hb}$ among under-five children being breastfed is significantly lower compared with under-five children who are not being breastfed. The reverse is the case for stunting, and it is not significant for wasting. Moreover, the prevalence of anemia and stunting among vaccinated children is significantly lower compared with under-five children who are not vaccinated. However, it is not significant for wasting. Thus, vaccinated children and those under breastfeeding are at lower risk of anemia and stunting compared with their counterparts. The prevalence of low $\mathrm{Hb}$ levels is significantly lower among children whose mothers had been working in the past one year before the survey compared with their counterparts. However, it is not significant for stunting and wasting.

The result indicates that the prevalence of low $\mathrm{Hb}$ level and stunting among children whose parents are married, living together, separated, divorced, and diseased spouse is not significantly different from children whose parents have never married. Unexpectedly, the risk is higher for wasting. The prevalence of stunting and wasting among children whose birth weight is at least $2.5 \mathrm{~kg}$ is significantly lower compared with children whose birth weight is below $2.5 \mathrm{~kg}$. However, it is not significant for anemia. 


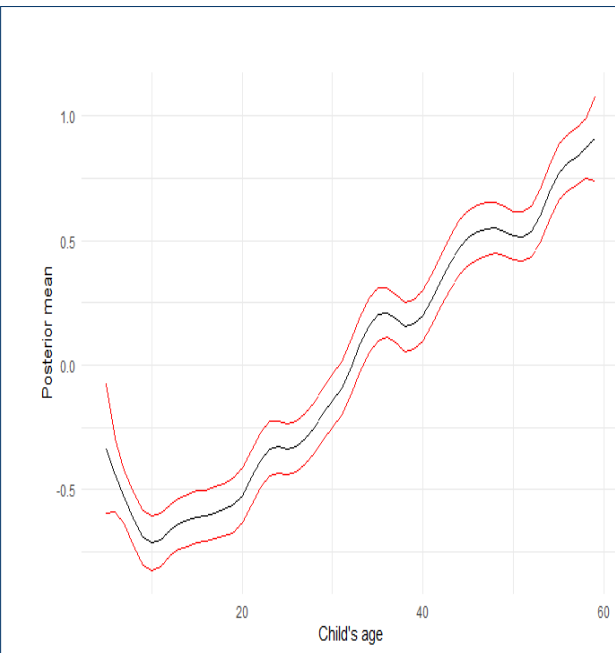

(a) anemia

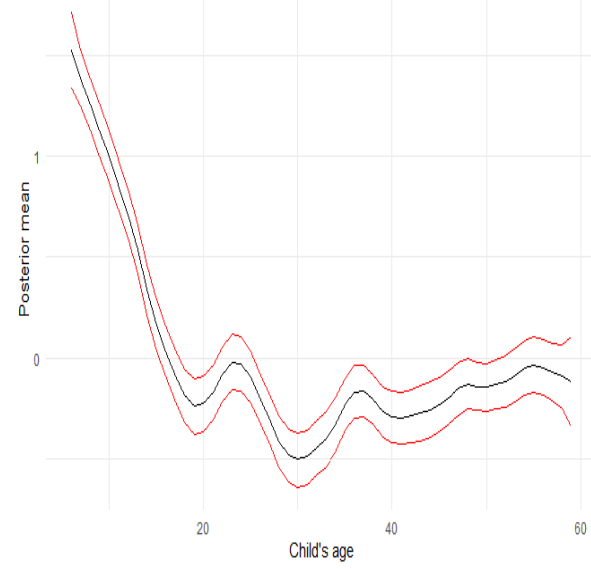

(c) stunting

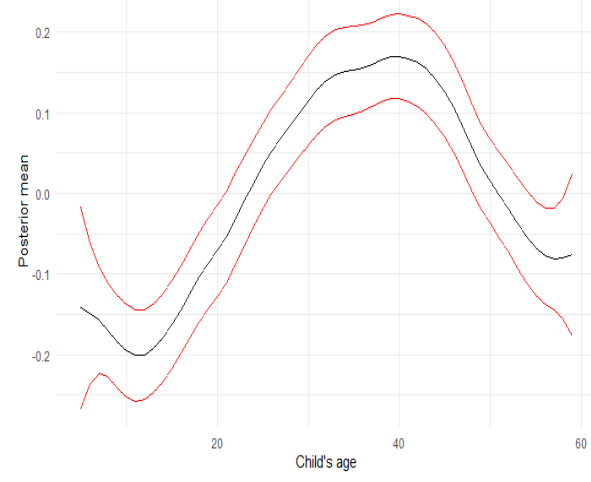

(e) wasting

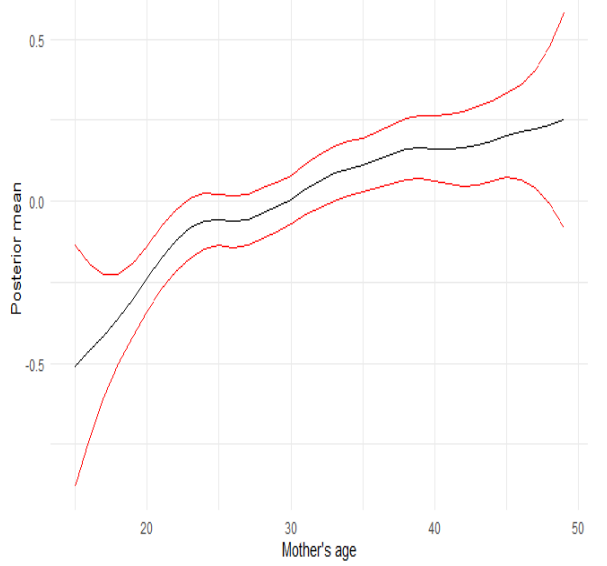

(b) anemia

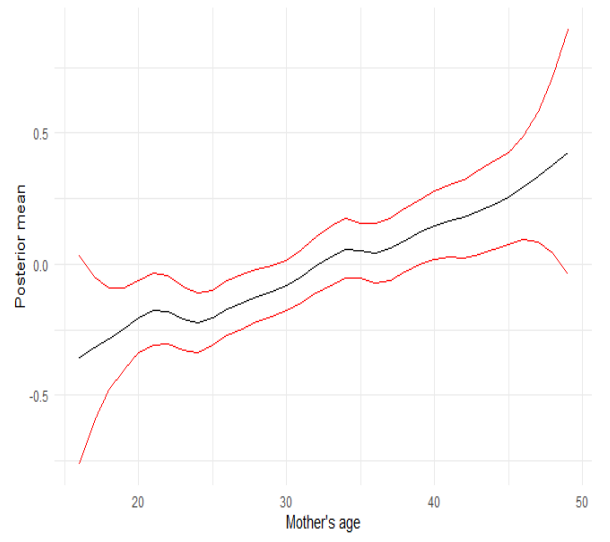

(d) stunting

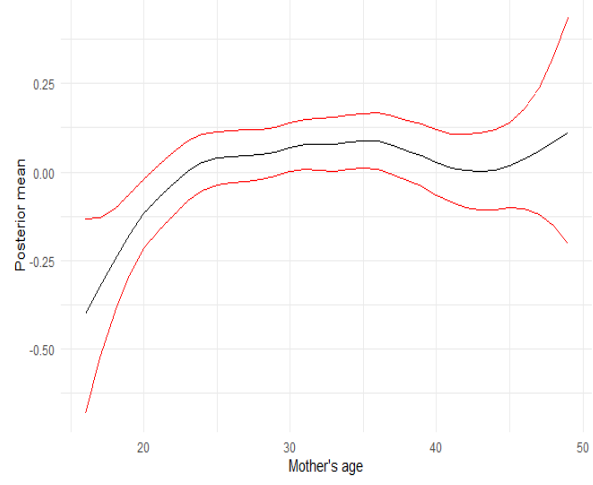

(f) wasting

Figure 2: The posterior estimates of the non-linear effects of single analysis of anemia, stunting and wasting. The middle black lines are the posterior mean and the red lines are the $95 \%$ credible intervals. An increment in the effects indicates lower prevalence/risk, while a decrease indicates higher prevalence/risk. 
Table 2: The posterior estimates of the fixed effects of the single analysis of anemia, stunting and wasting. Factors with non-inclusion of zero in the $95 \%$ credible intervals are considered significant. A higher value of the posterior mean indicates lower prevalence/risk.

\begin{tabular}{|c|c|c|c|c|c|c|c|c|c|}
\hline \multirow[t]{2}{*}{ Variables } & Mean & $2.5 \%$ & $97.5 \%$ & Mean & $2.5 \%$ & $97.5 \%$ & Mean & $2.5 \%$ & $97.5 \%$ \\
\hline & \multicolumn{3}{|c|}{$\begin{array}{r}2.5 \% \\
\text { Anemia }\end{array}$} & \multicolumn{3}{|c|}{ Stunting } & \multicolumn{3}{|c|}{ Wasting } \\
\hline Gender & & & & & & & & & \\
\hline Female & Reference & & & & & & & & \\
\hline Male & -0.060 & -0.114 & -0.006 & -0.100 & -0.149 & -0.052 & -0.102 & -0.139 & -0.066 \\
\hline Mother's Education level & & & & & & & & & \\
\hline No formal education & Reference & & & & & & & & \\
\hline Primary & 0.133 & 0.063 & 0.203 & 0.123 & 0.060 & 0.186 & 0.094 & 0.047 & 0.141 \\
\hline Secondary & 0.286 & 0.138 & 0.433 & 0.277 & 0.143 & 0.411 & 0.123 & 0.023 & 0.223 \\
\hline Higher & 0.377 & 0.173 & 0.581 & 0.444 & 0.260 & 0.629 & 0.283 & 0.144 & 0.421 \\
\hline $\begin{array}{l}\text { Wealth Quantile } \\
\text { Poorest }\end{array}$ & Reference & & & & & & & & \\
\hline Poorer & 0.329 & 0.246 & 0.412 & -0.055 & -0.129 & 0.018 & 0.068 & 0.013 & 0.124 \\
\hline Middle & 0.543 & 0.453 & 0.632 & 0.086 & 0.006 & 0.165 & 0.134 & 0.075 & 0.194 \\
\hline Rich & 0.517 & 0.419 & 0.615 & 0.159 & 0.073 & 0.245 & 0.206 & 0.142 & 0.271 \\
\hline Richest & 0.624 & 0.484 & 0.764 & 0.269 & 0.145 & 0.392 & 0.329 & 0.236 & 0.421 \\
\hline Water source & & & & & & & & & \\
\hline Unimproved & Reference & & & & & & & & \\
\hline $\begin{array}{l}\text { Improved } \\
\text { Toilet Facility }\end{array}$ & 0.081 & 0.017 & 0.145 & -0.066 & -0.121 & -0.010 & -0.057 & -0.098 & -0.015 \\
\hline Unimproved & Reference & & & & & & & & \\
\hline Improved & 0.078 & -0.013 & 0.169 & 0.188 & 0.105 & 0.270 & 0.035 & -0.027 & 0.097 \\
\hline $\begin{array}{l}\text { Settlement } \\
\text { Rural }\end{array}$ & Reference & & & & & & & & \\
\hline Urban & -0.111 & -0.240 & 0.018 & 0.037 & -0.074 & 0.149 & -0.151 & -0.234 & -0.068 \\
\hline $\begin{array}{l}\text { Mass Media usage } \\
\text { No }\end{array}$ & Reference & & & & & & & & \\
\hline Yes & 0.017 & -0.050 & 0.084 & 0.103 & 0.042 & 0.163 & 0.060 & 0.015 & 0.106 \\
\hline $\begin{array}{l}\text { Child Had Diarriah in the last } 2 \text { weeks } \\
\text { No }\end{array}$ & Reference & & & & & & & & \\
\hline Yes & -0.051 & -0.135 & 0.032 & -0.125 & -0.200 & -0.049 & -0.158 & -0.214 & -0.101 \\
\hline $\begin{array}{l}\text { Yes } \\
\text { Child Had Cough in the last } 2 \text { weeks }\end{array}$ & -0.198 & -0.285 & -0.110 & -0.134 & -0.213 & -0.054 & -0.207 & -0.267 & -0.148 \\
\hline No & Reference & & & & & & & & \\
\hline Yes & 0.066 & -0.017 & 0.149 & 0.014 & -0.061 & 0.088 & 0.021 & -0.035 & 0.077 \\
\hline Number of Children under 5 & Reference & & & & & & & & \\
\hline $2-3$ & -0.108 & -0.195 & -0.022 & 0.064 & -0.014 & 0.142 & -0.028 & -0.086 & 0.031 \\
\hline $\begin{array}{l}4+ \\
\text { Birth Order }\end{array}$ & -0.203 & -0.404 & -0.001 & 0.229 & 0.048 & 0.411 & -0.121 & -0.256 & 0.015 \\
\hline 年 & 0.230 & 0.124 & 0.335 & 0.220 & 0.124 & 0.316 & 0.041 & -0.030 & 0.113 \\
\hline $\begin{array}{l}2-4 \\
5+ \\
\text { Time in months of preceding Birth }\end{array}$ & $\begin{array}{l}\text { Reference } \\
-0.101\end{array}$ & -0.181 & -0.020 & -0.068 & -0.141 & 0.004 & -0.060 & -0.115 & -0.006 \\
\hline $\begin{array}{l}\text { Time in months of preceding Birth } \\
\text { less than } 25\end{array}$ & Reference & & & & & & & & \\
\hline $25-60$ & 0.160 & 0.086 & 0.234 & 0.173 & 0.106 & 0.240 & -0.033 & -0.084 & 0.017 \\
\hline $\begin{array}{l}61+ \\
\text { Freguency of Antenatal Yisit }\end{array}$ & 0.217 & 0.096 & 0.337 & 0.394 & 0.284 & 0.503 & 0.055 & -0.027 & 0.137 \\
\hline 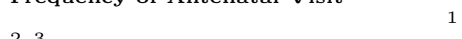 & 0.121 & 0.035 & 0.206 & -0.200 & -0.278 & -0.123 & 0.002 & -0.056 & 0.060 \\
\hline $\begin{array}{l}2-3 \\
4+ \\
\text { Contraceptive Used }\end{array}$ & -0.145 & -0.429 & 0.139 & 0.693 & 0.438 & 0.948 & -0.016 & -0.207 & 0.176 \\
\hline None & Reference & & & & & & & & \\
\hline Traditional & 0.123 & -0.193 & 0.438 & 0.007 & -0.278 & 0.291 & 0.233 & 0.020 & 0.447 \\
\hline Modern & 0.328 & 0.258 & 0.399 & 0.127 & 0.064 & 0.189 & 0.115 & 0.068 & 0.162 \\
\hline Child being Breasfed & & & & & & & & & \\
\hline No & Reference & & & & & & & & \\
\hline $\begin{array}{l}\text { Yes } \\
\text { Child was Vacinated }\end{array}$ & 0.140 & 0.074 & 0.206 & -0.240 & -0.299 & -0.180 & -0.011 & -0.055 & 0.034 \\
\hline $\begin{array}{l}\text { Child was Vacinated } \\
\text { No }\end{array}$ & Reference & & & & & & & & \\
\hline Yes & 0.092 & 0.032 & 0.153 & 0.058 & 0.004 & 0.112 & 0.033 & -0.008 & 0.073 \\
\hline $\begin{array}{l}\text { Postnatal Visit } \\
\text { No }\end{array}$ & Reference & & & & & & & & \\
\hline $\begin{array}{l}\text { No } \\
\text { Yes }\end{array}$ & $\begin{array}{l}\text { Reference } \\
-0.057\end{array}$ & -0.188 & 0.073 & -0.138 & -0.256 & -0.020 & 0.053 & -0.036 & 0.141 \\
\hline Mother works in the last 1 year & & & & & & & & & \\
\hline No & Reference & & & & & & & & \\
\hline Yes & 0.190 & 0.128 & 0.253 & -0.017 & -0.073 & 0.039 & 0.041 & -0.001 & 0.082 \\
\hline Marital status & & & & & & & & & \\
\hline Never married & Reference & & & & & & & & \\
\hline Married/leaving together & -0.013 & -0.169 & 0.144 & -0.128 & -0.268 & 0.012 & -0.154 & -0.258 & -0.050 \\
\hline Seperated/Devoiced/Spouse diseased & -0.058 & -0.248 & 0.132 & -0.143 & -0.314 & 0.027 & -0.136 & -0.263 & -0.009 \\
\hline Birthweight & & & & & & & & & \\
\hline less than 2.5 & Reference & & & & & & & & \\
\hline $2.5-4.5$ & 0.091 & -0.017 & 0.199 & 0.194 & 0.096 & 0.291 & 0.204 & 0.131 & 0.277 \\
\hline $4.5+$ & 0.093 & -0.200 & 0.386 & 0.512 & 0.245 & 0.778 & 0.454 & 0.254 & 0.654 \\
\hline
\end{tabular}

Turning attention to the non-linear effect of child age and maternal age, the prevalence of low Hb level (Figure 2a \& b ), stunting (Figure 2c \& d), and wasting (Figure $2 \mathrm{~d} \& \mathrm{e}$ ) are presented. The middle black line indicates the posterior mean, and the red lines indicate the $95 \%$ credible intervals. In Figure 2a, the prevalence of low Hb level first increases between 6 and 10 months. Then, the curve picks up, and the prevalence consistently decreases until age 35 . It became steady in the following two months. It further picks up, and the prevalence decreases until 45 months and 
again remains steady for the next four months, where the curve picks up, and the prevalence further decreases until age 59 months. In general, from 10 months and above, the curve is non-decreasing, except between age 35 to 40 months. It implies that the risk of anemia among under-five children decreases almost at a constant rate with an increase in age. Similarly, in Figure $2 \mathrm{~b}$, the prevalence of $\mathrm{Hb}$ level of children decreases at a constant rate between maternal ages 15 and 25 years. It remains constant for an additional two years, and then, gradually increases until age 49. It indicates that as mothers get older, the risk of anemia among children decreases. This is expected, since, as mothers get older, they gather more experience on positive attitudes towards parenting and a child's health.

In Figure 2c, the prevalence of stunting increases at a constant rate until age 20 months, where the curve behaves sinusoidal around the same risk until age 35 months, and then slowly increases unit age 59 months. This result indicates that at the fifth birthday, the risk of stunting is more severe compared with the risk of stunting before age 15 months. In Figure 2d, the prevalence of stunting has a similar pattern to the prevalence of anemia according to maternal age. That is, the risk of stunting decreases at a constant rate as maternal age increases.

In Figure 2e, the prevalence of wasting increased for the first five months and then recovered after additional five months. It keeps decreasing until a child attains 40 months, where it further increases at a constant rate until age 59 months. It indicates that the risk of wasting fluctuates between birth and the fifth birthday. In Figure 2f, the prevalence of wasting decreases at a constant rate as maternal age increases until 25, where it remains constant for additional fifteen months. It further slowly increases till age 43 and then decreases until 49 years.

Figure 3 presents the smoothed spatial effect on Hb level (Figure 3a), stunting (3b), and wasting (3c) across Ethiopia. The orange and red-colored regions indicate high prevalent regions in Ethiopia. Consequently, children residing in these regions are at severe risk of these ailments. The green and the blue regions indicate regions where the prevalence of these ailments is least severe. On the right side of Figure 3a the Southern Tigray, Eastern Amhara, and nearly the whole of Afar share a larger amount of the burden of the prevalence of low $\mathrm{Hb}$, and consequently, high anemia. On the left side of the map, Benishangul-gumuz and the North-East of Oromia shared a larger burden of the prevalence of low Hb. However, in Southern Ethiopia, a small ethnic group of the South-Eastern Oromia and South Somali are among the high-prevalent regions of anemia. However, in Figure 3b, southern Ethiopia has the highest burden of stunting, except for a small region towards the South of Oromia. From the North in the same graph, Western Tigray and Northern Amhara are the high burden regions, and consequently, these regions are high-risk regions of stunting. In Figure 3c, Somali, Harar, Dire Dawa and part of Oromia, Benishangul Gumuz, Amhara, southern Tigray, west of Afar are the high burden regions of wasting. Consequently, there is a high risk of wasting in these regions.

\section{Joint analysis of Anemia and Malnutrition}

The posterior mean and the credible intervals for the joint analysis of anemia and stunting, and anemia and wasting are presented in Table 3. The joint analysis is 


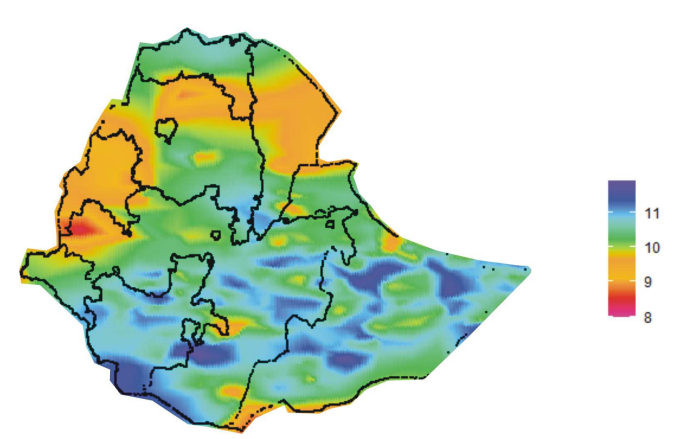

(a) anemia

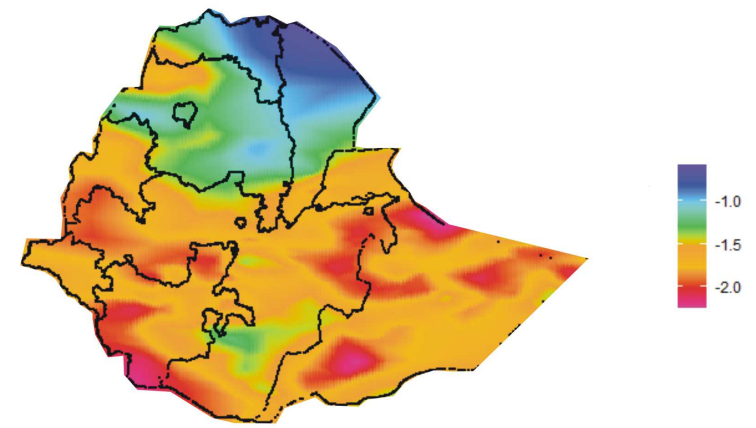

(b) stunting

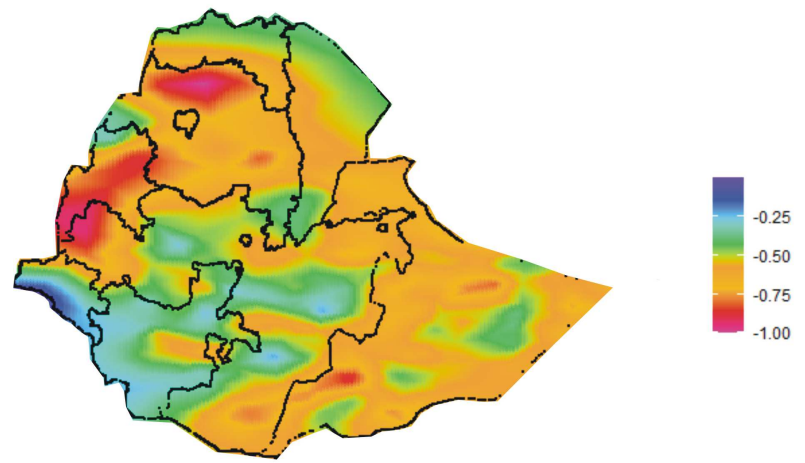

(c) wasting

Figure 3: The spatial effect of anemia, stunting and wasting. The red regions indicate the region with higher prevalence/risk, and the blue regions indicate the region with low prevalence/risk.

denoted as "Anemia \& Stunting" and "Anemia \& Wasting" respectively. The noninclusion of zero in the credible interval is used to determine the significance of the risk factors. 
In Table 3, male children are significantly more at risk of the co-occurrence of anemia and stunting, and anemia and wasting compared with female children. Thus, the prevalence of both ailments among male children is significantly higher. Furthermore, higher maternal education level and wealth index significantly lower the prevalence of anemia and stunting, and anemia and wasting. While improved water sources significantly lower the prevalence of simultaneous occurrences of anemia and stunting, and anemia and wasting, improved toilet facility does not. Thus, improving toilet facilities would not simultaneously lower the risk of both ailments. The place of settlement is not significant for anemia and stunting. However, it is different for anemia and wasting. Surprisingly, the prevalence of the co-occurrence of anemia and wasting among children living in the urban region is significantly higher compared with children living in the rural region. While mass media usage could significantly lower the prevalence of co-occurrence of anemia and wasting, it is not significant for anemia and stunting. Thus, improvement in mass media usage is not sufficient to lower the risk of co-occurrence of anemia and stunting. The prevalence of anemia and wasting among under-five children with diarrhea or fever is significantly higher compared with those without diarrhea or fever, and thus, they are more at risk. Moreover, the prevalence of anemia and stunting among under-five children with fever is significantly higher compared with under-five children without fever.

The co-occurrence of anemia and stunting, and anemia and wasting are significantly more prevalent with an increase in the number of under-five children in the household. Similarly, the prevalence of the co-occurrence of these ailments is significantly higher among children with higher birth order and lower among children with lower birth order. Thus, a higher number of under-five children in the household and higher birth order are determinants of the co-occurrence of these ailments. While the time of preceding birth above 25 months significantly lowers the prevalence of anemia and stunting, preceding birth above 61 months lowers the prevalence of anemia and wasting. That is, increasing birth interval is a crucial decision to reduce the prevalence of these ailments, and thus, reduce the risk. The frequency of antenatal care utilization is not significant, consequently, the prevalence of the co-occurrence of these ailments will be unable to be significantly diminished by merely increasing the number of antenatal care visits. A similar result is found for postnatal care utilization and child being breastfed. The prevalence of the co-occurrence of anemia and stunting, and anemia and wasting are significantly lower among children whose parents use a modern type of contraceptive compared with children whose parents do not use contraceptives.

Furthermore, the prevalence of both anemia and stunting, and anemia and wasting is significantly lower among vaccinated under-five children and whose mothers had been working since the past year compared with their counterparts. Thus, increasing the number of vaccinated children would significantly lower the risk of co-occurrence of these ailments. Unexpectedly, the prevalence of anemia and stunting, and anemia and wasting significantly increases among under-five children whose parents are married/cohabited couples, divorced, separated, or spouse diseased compared with their counterpart, which is no union. Co-occurrence of anemia and wasting is significantly less prevalent among under-five children with a birth weight greater than 
$2.5 \mathrm{~kg}$ compared with children whose birth weight is less than $2.5 \mathrm{~kg}$. A similar result is obtained for the prevalence of anemia and stunting, except that the prevalence among under-five children with birth weight above 4.5 is not significantly different from the prevalence among under-five children below $2.5 \mathrm{~kg}$. This is expected since lower birth weight and overweight are serious health problems among young children. Thus, children with birth weights between 2.5 and 4.5 are at lower risk of the co-occurrence of these ailments.

Table 3: The Joint analysis of anemia and stunting, and anemia and wasting. Factors with non-inclusion of zero in the $95 \%$ credible interval are considered significant risk factors to the prevalence of both ailments.

\begin{tabular}{|c|c|c|c|c|c|c|}
\hline \multirow[t]{2}{*}{ Variables } & Mean & $2.5 \%$ & \multirow{2}{*}{$\begin{array}{l}97.5 \% \\
\mathrm{ng}\end{array}$} & \multirow{2}{*}{\multicolumn{3}{|c|}{$\begin{array}{c}\text { Mean } \mathbf{2 . 5 \%} \quad \mathbf{9 7 . 5 \%} \\
\text { Anemia \& wasting }\end{array}$}} \\
\hline & Anen & \& \& Stun & & & & \\
\hline \multicolumn{7}{|l|}{ Gender } \\
\hline Female & Reference & & & & & \\
\hline Male & -0.055 & -0.082 & -0.028 & -0.068 & -0.092 & -0.045 \\
\hline \multicolumn{7}{|l|}{ Maternal Education level } \\
\hline Primary & 0.06 & 0.024 & 0.096 & 0.062 & 0.031 & 0.093 \\
\hline Secondary & 0.141 & 0.066 & 0.217 & 0.117 & 0.051 & 0.183 \\
\hline Higher & 0.196 & 0.091 & 0.301 & 0.191 & 0.099 & 0.282 \\
\hline \multicolumn{7}{|l|}{ Wealth Quantile } \\
\hline Poorer & 0.13 & 0.088 & 0.172 & 0.125 & 0.089 & 0.162 \\
\hline Middle & 0.25 & 0.204 & 0.296 & 0.228 & 0.188 & 0.268 \\
\hline Rich & 0.253 & 0.203 & 0.303 & 0.244 & 0.201 & 0.288 \\
\hline Richest & 0.31 & 0.238 & 0.382 & 0.312 & 0.25 & 0.375 \\
\hline \multicolumn{7}{|l|}{ Water source } \\
\hline Unimproved & Reference & & & & & \\
\hline & \multicolumn{6}{|c|}{ Toilet Facility } \\
\hline Unimproved & Reference & & & & & \\
\hline \multicolumn{6}{|l|}{ Settlement } & 0.033 \\
\hline Rural & Reference & & & & & \\
\hline \multicolumn{5}{|l|}{ Mass Media usage } & -0.154 & -0.036 \\
\hline No & Reference & & & & & \\
\hline \multirow{2}{*}{\multicolumn{7}{|c|}{ Child Had Diarrhea in the last 2 weeks }} \\
\hline & & & & & & \\
\hline $\begin{array}{l}\text { Yes } \\
\text { Child Had Fever in the last } 2 \text { weeks } \\
\text { No }\end{array}$ & \multicolumn{2}{|c|}{ Child Had Fever in the last 2 weeks } & 0.007 & -0.067 & -0.105 & -0.03 \\
\hline Yes & -0.103 & -0.147 & -0.058 & -0.134 & -0.173 & -0.095 \\
\hline \multicolumn{7}{|l|}{ Child Had Cough in the last 2 weeks } \\
\hline Yes & 0.023 & -0.019 & 0.065 & 0.02 & -0.016 & 0.057 \\
\hline Number of Children under 5 & & & & & & \\
\hline 1 & Reference & & & & & \\
\hline $2-3$ & -0.091 & -0.133 & -0.049 & -0.086 & -0.123 & -0.05 \\
\hline $\begin{array}{l}4+ \\
\text { Birth Order }\end{array}$ & -0.135 & -0.237 & -0.033 & -0.154 & -0.243 & -0.065 \\
\hline 1 & 0.098 & 0.045 & 0.151 & 0.061 & 0.015 & 0.107 \\
\hline $2-4$ & Reference & & & & & \\
\hline $\begin{array}{l}5+ \\
\text { Time in months of preceding Birth }\end{array}$ & -0.089 & -0.129 & -0.048 & -0.081 & -0.116 & -0.046 \\
\hline less than 25 & Reference & & & & & \\
\hline $25-60$ & 0.074 & 0.037 & 0.112 & 0.023 & -0.01 & 0.055 \\
\hline $\begin{array}{l}61+ \\
\text { Frequency of Antenatal Visit }\end{array}$ & 0.117 & 0.056 & 0.178 & 0.059 & 0.006 & 0.112 \\
\hline $\begin{array}{l}1 \\
2-3\end{array}$ & -0.023 & -0.065 & 0.019 & 0.003 & -0.033 & 0.04 \\
\hline $4+$ & 0.012 & -0.134 & 0.158 & -0.071 & -0.198 & 0.056 \\
\hline $\begin{array}{l}\text { Contraceptive Used } \\
\text { None }\end{array}$ & Reference & & & & & \\
\hline Traditional & 0.058 & -0.104 & 0.22 & 0.132 & -0.009 & 0.272 \\
\hline Modern & 0.157 & 0.121 & 0.193 & 0.141 & 0.109 & 0.172 \\
\hline Child being Breastfed & & & & & & \\
\hline No & Reference & & & & & \\
\hline Yes & 0.011 & -0.023 & 0.044 & 0.027 & -0.002 & 0.056 \\
\hline Child was Vaccinated & & & & & & \\
\hline No & Reference & & & & & \\
\hline Yes & 0.061 & 0.032 & 0.09 & 0.056 & 0.031 & 0.081 \\
\hline Postnatal Visit & & & & & & \\
\hline No & Reference & & & & & \\
\hline Yes & -0.058 & -0.125 & 0.009 & -0.014 & -0.072 & 0.044 \\
\hline Mother works in the last 1 year & & & & & & \\
\hline $\begin{array}{l}\text { No } \\
\text { Yes }\end{array}$ & Reference & 0043 & 0.107 & 0072 & 0.044 & 0.1 \\
\hline Marital status & 0.075 & 0.043 & 0.107 & 0.072 & 0.044 & 0.1 \\
\hline Never married & Reference & & & & & \\
\hline Married/leaving together & -0.269 & -0.326 & -0.211 & -0.259 & -0.309 & -0.21 \\
\hline Separated/Divorced/Spouse diseased & -0.29 & -0.37 & -0.21 & -0.264 & -0.333 & -0.195 \\
\hline Birth weight & & & & & & \\
\hline less than 2.5 & Reference & & & & & \\
\hline $2.5-4.5$ & 0.056 & 0 & 0.111 & 0.093 & 0.045 & 0.141 \\
\hline $4.5+$ & 0.104 & -0.047 & 0.255 & 0.181 & 0.05 & 0.312 \\
\hline
\end{tabular}


Turning attention to the non-linear effects, Figure 4 presents the effect of child and maternal age on the joint prevalence of anemia and stunting, and anemia and wasting. The middle black line represents the posterior mean, and the red lines indicate the $95 \%$ credible interval. For emphasis, it is important to note that an increase in posterior estimates implies decreased prevalence, while a decrease in posterior estimates indicates increased prevalence.

Figure 4a presents the effect of child's age on the prevalence of anemia and stunting. The curve is overshadowed by the shape of the child's age on the risk of anemia. However, it has a longer downward duration from age 6 . The prevalence of anemia and stunting increased almost at a constant rate from 6 months to 20 months and gradually decreases in a sinusoidal form until a child attains 59 months. A similar pattern is also found for anemia and wasting (Figure 4c). It indicates that the severity of the simultaneous impact of anemia and stunting, and anemia and wasting in the well-being of children diminishes as they get older. Results also revealed a more influence of anemia in the health status of children compared with stunting and wasting. Figure $4 \mathrm{~b} \& \mathrm{c}$ present the effect of maternal age on the prevalence of anemia and stunting, and anemia and wasting. In Figure 4b, as the maternal age increases, the prevalence of anemia and stunting increases, and thus, the risk increases. A similar pattern is found for the joint prevalence of anemia and wasting. 


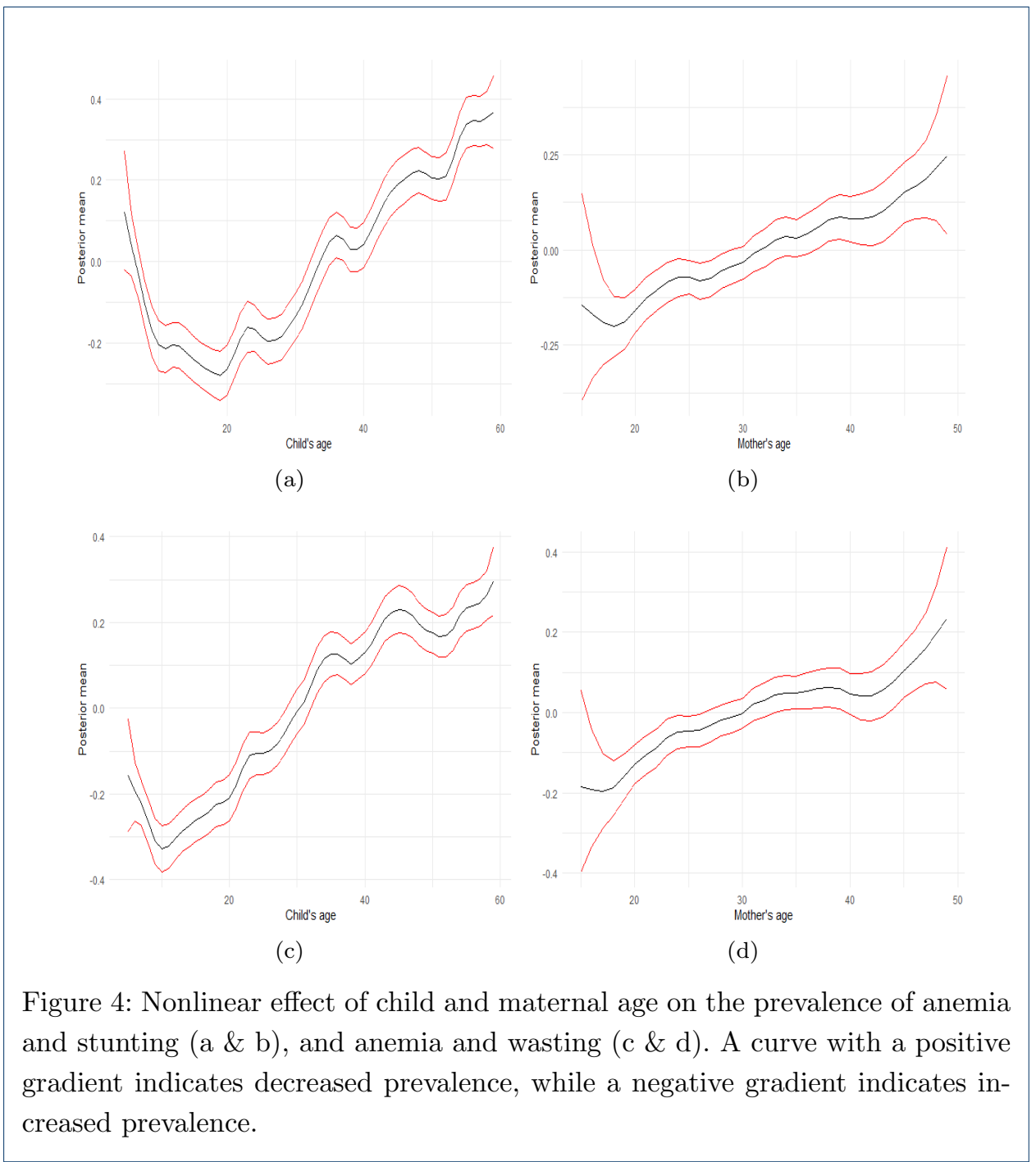

Figure 5 presents the smoothed spatial effect of the co-occurrence of anemia and stunting (Figure 5a) and anemia and wasting (Figure 5b) across Ethiopia. The orange and red-colored regions indicate high prevalent regions. That is, children residing in these regions are at severe risk of the co-occurrence of these ailments. From Figure 5a, the Northern Gambela, Western Oromia, Northeast Benishangulgumuz, Central and Northern Amhara, Southern Afar, and parts of Somali are the high burden region in the joint prevalence of anemia and stunting. A similar spatial pattern is found for anemia and wasting in Ethiopia. 


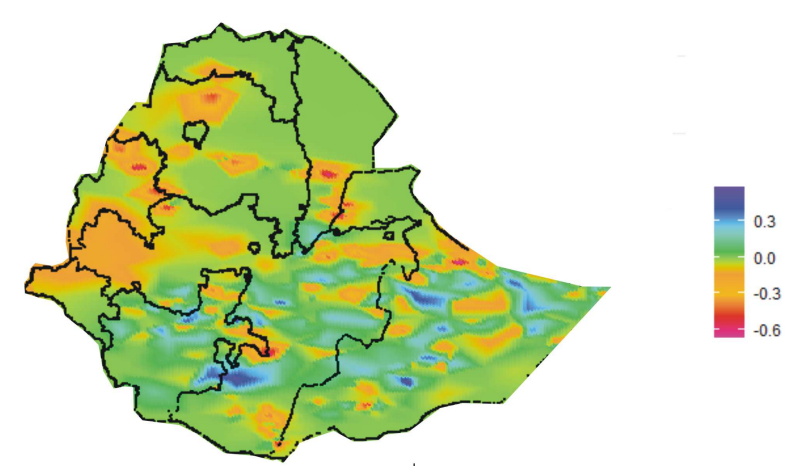

(a)

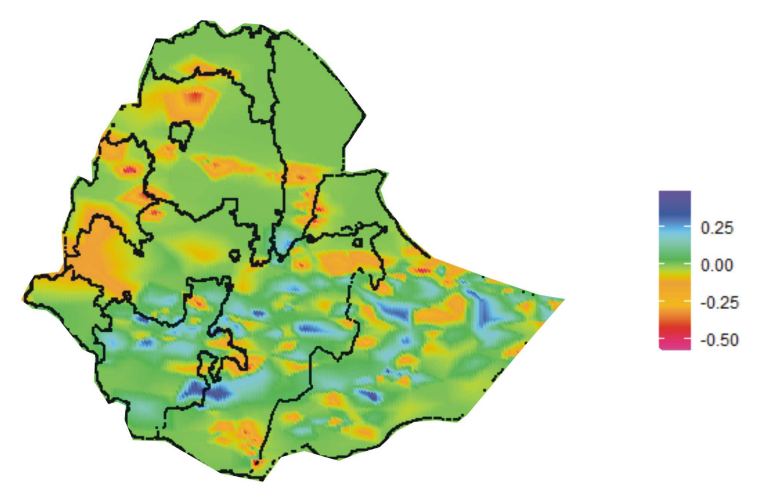

(b)

Figure 5: Spatial effect on the joint prevalence of anemia and stunting (a), and anemia and wasting (b). The red spot indicates the region with a high prevalence of both ailments.

\section{Discussion}

This study examined the association between anemia and malnutrition to ascertain significance in the co-occurrence of both ailments among under-five children in Ethiopia. A Chi-squared test of association and an unconditional exact test were first adopted to check for association in the occurrence of these ailments among under-five children. The result indicated a significant association across age-group of 20 months intervals. Thus, this study adopted a Bayesian hierarchical mixed effect model to account for the uncertainty in the joint occurrence of anemia and malnutrition among under-five children in Ethiopia. The spatial pattern was modeled with a stochastic partial differential equation which allows continuous interpolation of the quantified prevalence over the whole country. In this sense, it facilitates the spatial localization of hotspots of anemia and malnutrition. In addition to the joint analysis, this study conducted a univariate analysis of anemia and malnutrition. The results from the joint analysis indicate the resultant impact of both ailments on the well-being of under-five children. It could be garnered from the result that factors that significantly increase the risk of anemia and malnutrition in a separate analysis are with certainty significant risk factors in the joint analysis. However, this is not the case when the risk factors are significant in either anemia or mal- 
nutrition. From the joint analysis, the main determinants of the co-occurrence are gender, maternal education, wealth quantile, water source, place of settlement, mass media, diarrhea and fever in the last two weeks, number of children under five, birth order, preceding birth, contraceptive used, vaccination, mother work in the past one year, marital status, and birth weight. Results also indicate a spatial disparity in the prevalence of the co-occurrence of both ailments. Higher prevalence was found among children below 20 months and younger maternal age.

Findings revealed a higher prevalence of the co-occurrence of anemia and stunting and anemia and wasting among male children compared with female children. This finding is consistent with existing literature, [34, 35]. This finding may suggest that male children are more vulnerable to health inequalities and could be more pronounced at the early stages after birth. This study found disparities in the prevalence of anemia and stunting and wasting across maternal education levels. The lower the maternal education, the higher the prevalence. This is expected as educated mothers are likely to seek experts on child well-being and have more understanding of child nutrition. This finding is in agreement with [36] and [37]. This finding indicates that maternal education is a key risk factor for projecting the co-occurrence of anemia and malnutrition among under-five children. Another key determinant factor is the wealth inequalities among Ethiopian households. The prevalence of the co-occurrence of anemia and malnutrition is high among the lower wealth quantile households. This finding is consistent with [38] and [39]. It is expected as children in households with low wealth quantile are faced with limited resources and lack access to nutritious diets. Moreover, the trend of wealth inequalities in Ethiopia is rising, [40], and might lead to an increase in the prevalence of anemia among under-five children in Ethiopia. Thus, household resource allocation and household diversification of business activities could help to measure up to the needs of under-five children, thereby reducing the risk of the co-occurrence of anemia and malnutrition.

The finding showed that unimproved household water source is a key factor to predict co-occurrence of anemia and malnutrition. There is a higher likelihood of the co-occurrence of anemia and malnutrition among households with unimproved water sources compared with the households with improved water sources. This finding agrees with [41] and [42]. Policies that strengthen access to improved water could lower the risk of the co-occurrence of anemia and stunting among underfive children. Unexpectedly, the finding indicates that the place of settlement is not sufficient to determine the risk of co-occurrence of anemia and stunting, but anemia and wasting. This followed from the single analysis, where urban settlement is a determining factor of increased risk of wasting in Ethiopia. This finding could be influenced by the heterogeneity among households in the urban region, as more rural occupants migrate to urban regions in search of greener pasture. A similar pattern is found for mass media usage. While mass media is not a determining factor for the co-occurrence of anemia and stunting, it significantly lowers the prevalence of anemia and wasting among households. Thus, policies that ensure enlightenment through mass media should be strengthened.

The finding showed that fever and diarrhea is a determining factor for predicting the prevalence of co-occurrence of anemia and malnutrition. It indicates a high 
prevalence of anemia and stunting and wasting among under-five children with fever. However, it only indicates a high prevalence of anemia and wasting among under-five children with diarrhea. These findings are consistent in a single analysis of anemia, [43] and malnutrition, [44]. Thus, the co-occurrence of anemia and malnutrition is most likely expected among children suffering from fever and diarrhea. Policies that straighten access to an improved water source, exclusive breastfeeding, improved sanitation, and health education, [45] could improve the health status of children suffering diarrhea and fever, therefore reducing the risk of anemia and malnutrition. This study also found that a higher number of under-five children in households and higher birth positions are key determinants to the prevalence of anemia and malnutrition. On one hand, the risk of the co-occurrence of both ailments increases as the number of household under-five children and the birth position increases. This could be linked to shared household limited resources among under-five children. On the other hand, an increase in the duration of preceding birth lowers the risk of cooccurrence. Thus, effective planned birth control could lower the number of underfive in households and consequently lower the birth order and increase birth spacing. This finding is in line with the results found in literature, [46]. Surprisingly, findings indicate that the frequency of antenatal care visits and postnatal care utilization does not lower the prevalence of the co-occurrence of anemia and malnutrition. Thus, there is a need for improvement of health care facilities, train and retrain qualified health practitioners. In this manner, the healthcare system could have a positive impact on the well-being of under-five children in Ethiopia.

Findings indicate a lower prevalence of the co-occurrence of anemia and malnutrition for birth weight within $2.5 \mathrm{~kg}$ and $4.5 \mathrm{~kg}$. Thus, children born with birth weight within the interval $(2.5,4.5) \mathrm{kg}$ are at lower risk of co-occurrence of anemia and malnutrition compared with birth weights within the interval $(0.5,2.5) \mathrm{kg}$. Moreover, the prevalence is lower among children with birth weight within the interval $(4.5,6.5) \mathrm{kg}$. This finding is consistent with the result found in Cuba, [47]. Another significant finding is the use of contraceptives. It shows that the use of modern contraceptives lowers the prevalence of the co-occurrence of anemia and malnutrition compared with no use. This could be linked to the effectiveness of modern contraceptives for birth control. It lowers unintended gestation and indirectly reduces the number of households under-five children, and increases birth spacing. However, it could also be associated with birth weights since studies have shown a strong association of unplanned pregnancies to low birth weight, [48]. As expected, vaccination significantly lowers the co-occurrence of anemia and malnutrition in Ethiopia. Thus, infant vaccination policies should be further strengthened. Finding also indicates that maternal employment lowers the risk of co-occurrences of these ailments. However, the result could be otherwise for infants, [49] since mothers would spend fewer quality times with their children. Unexpectedly, findings indicate that marriage, cohabitation, separation, and spouse diseased increases the risk of co-occurrence of anemia and malnutrition. Thus, there is a need for further investigation since studies have shown a positive relationship between marriage and the well-being and development of children, [50].

Furthermore, this study found that the prevalence of anemia and stunting first increases in the first twenty months after birth, and consequently, the risk increases. 
Moreover, the prevalence lowers gradually from 20 months until 59 months. This finding is consistent with the literature, [51]. For anemia and stunting, this finding suggests a wide food coverage, supplementation, and fortification for children within the first twenty months after birth and within the first ten months for the co-occurrence of anemia and wasting. The prevalence of anemia and malnutrition reduces as the mother gets older and garnered experience. Thus, this finding suggests parental support to young mothers for the well-being and development of their children. In this manner, the risk of these ailments can be contained.

This study found a geographical disparity in the prevalence of anemia and malnutrition in Ethiopia. The finding identified northeast Ethiopia and sub-regions in the South as the regions with a severe burden of the co-occurrence of anemia and malnutrition. These regions include Northern Gambela, Western Oromia, Northeast Benishangul-gumuz, Central and Northern Amhara, Southern Afar, and parts of Somali. These maps are vital since they indicate the regions with the possibility of fighting anemia and malnutrition simultaneously and the locations where this is unlikely realistic. In this way, programs and policies will not miss the opportunity of simultaneous intervention.

\section{Conclusion}

This study adopted a Bayesian hierarchical mixed model, using a stochastic partial differential equation to estimate the spatial pattern of the co-occurrence of anemia and malnutrition. It was aimed to determine the key risk factors predicting the co-occurrence of anemia and malnutrition among under-five children in Ethiopia. This study found the common risk factors increasing the risk of the co-occurrence of anemia and malnutrition, which includes gender, maternal educational level, family wealth index, number of under-five children, birth order, time of preceding birth, contraceptive used, vaccination, birth weight of children, child's age and mother's age. Additionally, this study found spatial disparity placing children residing in Northern Gambela, Western Oromia, Northeast Benishangul-gumuz, Central and Northern Amhara, Southern Afar, and parts of Somali regions at higher risk. These findings could be utilized by policymakers and intervention programs to simultaneously tackle and contain the prevalence of both ailments. For instance, giving a basic education program that enlightens mothers on the benefits of modern types of contraceptives, appropriate birth spacing, infant vaccination, and educating mothers or caregivers on better parental attitude. In this way, anemia and malnutrition can be simultaneously contained in the identified high prevalent parts of Ethiopia. For cost-effective intervention, policies and programs that improve individual-level risk factors of parents and caregivers are a more promising approach to tackle high prevalent regions than the ones on the children and should be considered as an utmost priority in the country.

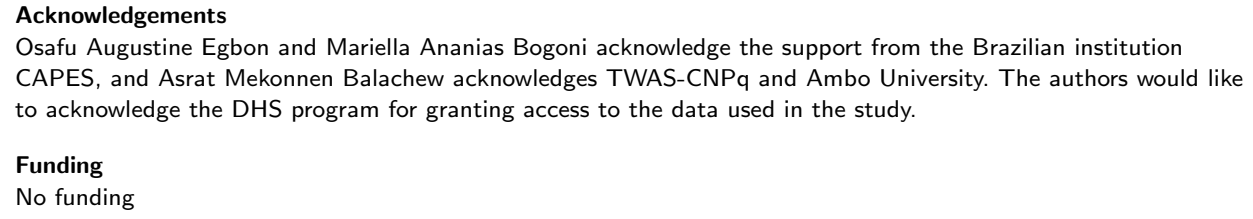




\section{Abbreviations}

PHC: Population and Housing Census DHS: Demographic and Health Survey EA : mEnumeration Areas EDHS Ethiopia Demographic and Health Survey HA: Height-for-age Hb: Hemoglobin WH : Weight-for-height WHO World Health Organization INLA: Integrated Nested Laplace Approximation SPDE: Stochastic Partial Differential Equation UPET: Unconditional Paired Exact Test

Availability of data and materials

The Ethiopia Demographic and health survey data used in this study are available and accessible on the DHS program website (http://dhsprogram.com).

Ethics approval and consent to participate

The data utilized in the study is from a publicly available source and hence ethics are not applicable.

Competing interests

The authors declare that they have no competing interests.

\section{Consent for publication}

Not applicable.

Authors' contributions

OAE conceived the study idea, $A M B$ and $M A B$ sourced the data, OAE performed the computation, $A M B$ and MAB validated the model. All authors participated in the manuscript writing, read and accepted the final manuscript revision.

Authors' information

Osafu Augustine Egbon ${ }^{1,3}$, Asrat Mekonnen Balechew ${ }^{1,2 *}$ and Mariella Ananias Bogoni ${ }^{1,3}$

Author details

${ }^{1}$ Institute of Mathematical and Computer Sciences, University of São Paulo, São Carlos, Brazil. ${ }^{2}$ Department of Mathematics, Ambo University, Ambo, Ethiopia. ${ }^{3}$ Department of Statistics, Universidade Federal de São Carlos, São Carlos, Brazil.

References

1. Unicef, et al.: Levels and trends in child malnutrition. Technical report, eSocialSciences (2018)

2. França, T., Ishikawa, L., Zorzella-Pezavento, S., Chiuso-Minicucci, F., da Cunha, M., Sartori, A.: Impact of malnutrition on immunity and infection. Journal of Venomous Animals and Toxins including Tropical Diseases 15(3), 374-390 (2009)

3. Walson, J.L., Berkley, J.A.: The impact of malnutrition on childhood infections. Current opinion in infectious diseases 31(3), 231 (2018)

4. Magalhaes, R.J.S., Clements, A.C.: Mapping the risk of anaemia in preschool-age children: the contribution of malnutrition, malaria, and helminth infections in west africa. PLoS Med 8(6), 1000438 (2011)

5. Victora, C.G., Adair, L., Fall, C., Hallal, P.C., Martorell, R., Richter, L., Sachdev, H.S., Maternal, Group, C.U.S., et al.: Maternal and child undernutrition: consequences for adult health and human capital. The lancet 371(9609), 340-357 (2008)

6. WHO, et al.: Unicef/who/the world bank group joint child malnutrition estimates: levels and trends in child malnutrition: key findings of the 2020 edition (2020)

7. Khatab, K.: Childhood malnutrition in egypt using geoadditive gaussian and latent variable models. The American journal of tropical medicine and hygiene 82(4), 653-663 (2010)

8. Kandala, N.-B., Madungu, T.P., Emina, J.B., Nzita, K.P., Cappuccio, F.P.: Malnutrition among children under the age of five in the democratic republic of congo (drc): does geographic location matter? BMC public health 11(1), 1-15 (2011)

9. Gayawan, E., Adebayo, S.B., Komolafe, A.A., Akomolafe, A.A.: Spatial distribution of malnutrition among children under five in nigeria: a bayesian quantile regression approach. Applied Spatial Analysis and Policy 12(2), 229-254 (2019)

10. Amegbor, P.M., Zhang, Z., Dalgaard, R., Sabel, C.E.: Multilevel and spatial analyses of childhood malnutrition in uganda: examining individual and contextual factors. Scientific reports 10(1), 1-15 (2020)

11. Egbon, O., Somo-Aina, O., Gayawan, E.: Spatial weighted analysis of malnutrition among children in nigeria: A bayesian approach. Statistics in Biosciences 35(4), 1-29 (2021). doi:10.1007/s12561-021-09303-9

12. Takele, K., Taye, A.: Bayesian modelling of growth retardation among children under-five years old. Far East Journal of Theoretical Statistics 48(2), 87 (2014)

13. Shebeshi, A., Asfaw, Z.: Bayesian spatial quantile interval model with application to childhood malnutrition in ethiopia (2020)

14. Takele, K., Zewotir, T., Ndanguza, D.: Spatial joint modelling of children under-five malnutrition in ethiopia. J Hum Ecol 70(1-3), 132-142 (2020)

15. De Benoist, B., Cogswell, M., Egli, I., McLean, E.: Worldwide prevalence of anaemia 1993-2005; who global database of anaemia (2008)

16. WHO, et al.: The global prevalence of anaemia in 2011. geneva: World health organization (2011)

17. Lindgren, F., Rue, H.: On the second-order random walk model for irregular locations. Scandinavian journal of statistics 35(4), 691-700 (2008)

18. Wang, J., Wang, H., Chang, S., Zhao, L., Fu, P., Yu, W., Man, Q., Scherpbier, R., Pan, L., Duan, Y., et al. The influence of malnutrition and micronutrient status on anemic risk in children under 3 years old in poor areas in china. PloS one 10(10), 0140840 (2015)

19. WHO: Anaemia in children i 5 years estimates by who region.

https://apps.who.int/gho/data/view.main.ANEMIACHILDRENREGv?lang=en (2019) 
20. McLean, E., Cogswell, M., Egli, I., Wojdyla, D., De Benoist, B.: Worldwide prevalence of anaemia, who vitamin and mineral nutrition information system, 1993-2005. Public health nutrition 12(4), 444-454 (2009)

21. EDHS: The 2016 Ethiopia Demographic and Health survey. https://dhsprogram.com/publications/publication-FR328-DHS-Final-Reports.cfm (2016)

22. Gayawan, E., Arogundade, E.D., Adebayo, S.B.: Possible determinants and spatial patterns of anaemia among young children in nigeria: a bayesian semi-parametric modelling. International health 6(1), 35-45 (2014)

23. Ejigu, B.A., Wencheko, E., Berhane, K.: Spatial pattern and determinants of anaemia in ethiopia. PloS one 13(5), 0197171 (2018)

24. Roberts, D.J., Matthews, G., Snow, R.W., Zewotir, T., Sartorius, B.: Investigating the spatial variation and risk factors of childhood anaemia in four sub-saharan african countries. BMC public health 20(1), 1-10 (2020)

25. Barry, T.S., Ngesa, O., Onyango, N.O., Mwambi, H.: Bayesian spatial modeling of anemia among children under 5 years in guinea. International Journal of Environmental Research and Public Health 18(12), 6447 (2021)

26. Tadesse, E., Ayele, T.: Spatial distribution and factors associated with childhood anemia in ethiopia (2020)

27. Adeyemi, R.A., Zewotir, T., Ramroop, S.: Joint spatial mapping of childhood anemia and malnutrition in sub-saharan africa: a cross-sectional study of small-scale geographical disparities. African health sciences 19(3) 2692-2712 (2019)

28. Alelign, T., Degarege, A., Erko, B.: Prevalence and factors associated with undernutrition and anaemia among school children in durbete town, northwest ethiopia. Archives of Public Health 73(1), 1-7 (2015)

29. Roba, K.T., O'Connor, T.P., Belachew, T., O'Brien, N.M.: Anemia and undernutrition among children aged 6-23 months in two agroecological zones of rural ethiopia. Pediatric health, medicine and therapeutics 7, 131 (2016)

30. EDHS: The 2011 Ethiopia Demographic and Health survey. https://dhsprogram.com/publications/publication-FR328-DHS-Final-Reports.cfm (2011)

31. Lindgren, F., Rue, H.: Bayesian spatial modelling with r-inla. Journal of statistical software 63(1), 1-25 (2015)

32. R Core Team: R: A Language and Environment for Statistical Computing. R Foundation for Statistical Computing, Vienna, Austria (2019). R Foundation for Statistical Computing. https://www.R-project.org/

33. National Academies of Sciences, Engineering, and Medicine and others: Parenting matters: Supporting parents of children ages 0-8 (2016)

34. Melku, M., Takele, W.W., Anlay, D.Z., Ekubagewargies, D.T., Getaneh, Z., Abebe, M., Abebe, Z.: Male and undernourished children were at high risk of anemia in ethiopia: a systematic review and meta-analysis. Italian journal of pediatrics 44(1), 1-11 (2018)

35. Wamani, H., Åstrøm, A.N., Peterson, S., Tumwine, J.K., Tylleskär, T.: Boys are more stunted than girls in sub-saharan africa: a meta-analysis of 16 demographic and health surveys. BMC pediatrics 7(1), 1-10 (2007)

36. Abuya, B.A., Ciera, J., Kimani-Murage, E.: Effect of mother's education on child's nutritional status in the slums of nairobi. BMC pediatrics 12(1), 1-10 (2012)

37. Iftikhar, A., Bari, A., Iqbal Bano, Q.M.: Impact of maternal education, employment and family size on nutritional status of children. Pakistan Journal of Medical Sciences 33(6), 1401 (2017)

38. Hong, R., Mishra, V.: Effect of wealth inequality on chronic under-nutrition in cambodian children. Journal of Health, Population and Nutrition, 89-99 (2006)

39. Hong, R., Banta, J.E., Betancourt, J.A.: Relationship between household wealth inequality and chronic childhood under-nutrition in bangladesh. International journal for equity in health 5(1), 1-10 (2006)

40. Debebe, S., Zekarias, E.H.: Analysis of poverty, income inequality and their effects on food insecurity in southern ethiopia. Agriculture \& Food Security 9(1), 1-12 (2020)

41. Kothari, M.T., Coile, A., Huestis, A., Pullum, T., Garrett, D., Engmann, C.: Exploring associations between water, sanitation, and anemia through 47 nationally representative demographic and health surveys. Annals of the New York Academy of Sciences 1450(1), 249 (2019)

42. van Cooten, M.H., Bilal, S.M., Gebremedhin, S., Spigt, M.: The association between acute malnutrition and water, sanitation, and hygiene among children aged 6-59 months in rural e thiopia. Maternal \& child nutrition 15(1), 12631 (2019)

43. Howard, C.T., de Pee, S., Sari, M., Bloem, M.W., Semba, R.D.: Association of diarrhea with anemia among children under age five living in rural areas of indonesia. Journal of tropical pediatrics 53(4), 238-244 (2007)

44. Guerrant, R.L., Schorling, J.B., McAuliffe, J.F., De Souza, M.A.: Diarrhea as a cause and an effect of malnutrition: diarrhea prevents catch-up growth and malnutrition increases diarrhea frequency and duration. The American journal of tropical medicine and hygiene 47(1 Pt 2), 28-35 (1992)

45. WHO: Fact sheet: Diarrhoea disease. https://www.who.int/news-room/fact-sheets/detail/diarrhoeal-disease (2017)

46. Rahman, M.: Association between order of birth and chronic malnutrition of children: a study of nationally representative bangladeshi sample. Cadernos de saude publica 32 (2016)

47. Pita, G.M., Jiménez, S., Basabe, B., García, R.G., Macías, C., Selva, L., Hernández, C., Cruz, M., Herrera, R., O'Farrill, R., et al.: Anemia in children under five years old in eastern cuba, 2005-2011. Medicc Review 16, 16-23 (2014)

48. Eggleston, E., Tsui, A.O., Kotelchuck, M.: Unintended pregnancy and low birthweight in ecuador. American journal of public health 91(5), 808 (2001)

49. Nankinga, O., Kwagala, B., Walakira, E.J.: Maternal employment and child nutritional status in uganda. PloS one 14(12), 0226720 (2019)

50. Ribar, D.C.: Why marriage matters for child wellbeing. The Future of Children, 11-27 (2015)

51. Belachew, A., Tewabe, T.: Under-five anemia and its associated factors with dietary diversity, food security, stunted, and deworming in ethiopia: systematic review and meta-analysis. Systematic reviews 9(1), 1-9 (2020) 